\title{
Una historia ambiental global: de las reservas forestales de la nación a las reservas de la biosfera en México ${ }^{1}$
}

\section{A Global Environmental History: From the Nation's Forest Reserves to Mexico's Biosphere Reserves}

\author{
Juan Humberto Urquiza García \\ Coordinación de Humanidades-Universidad Nacional Autónoma de México, \\ Ciudad de México, México \\ humberto.urquiza@flacso.edu.mx \\ ORCID: https://orcid.org/oooo-0003-489I-8606 \\ ISSN-OI85-4259; e- ISSN: 2007-9176 \\ DOI: http://dx.doi.org/10.28928/ri/872019/atc4/urquizagarciah
}

\begin{abstract}
Resumen:
La conservación de los recursos naturales es una preocupación que se refleja hoy en la agenda internacional. Es importante señalar que desde el siglo XIx ha sido parte de las reflexiones de las comunidades científicas en diferentes latitudes. Podemos decir que la preocupación por la conservación tiene diferentes etapas históricas, que han dependido del valor asignado a la naturaleza y sus recursos. En México, la preocupación por la conservación, de igual forma que en otros países, estuvo presente desde finales del siglo xviII. Este artículo tiene como objetivo revisar la relación entre el conservacionismo mexicano y ciertos debates internacionales sobre el tema; pretende dar cuenta de cómo esta preocupación ha tenido diferentes momentos y se ha materializado en lo que ahora se conoce como parques nacionales, reservas forestales, santuarios de vida silvestre o reservas de la biosfera. Esta es una pequeña historia global de una ciencia híbrida y de cómo se expresó en lo que hoy llamamos áreas naturales protegidas.

Palabras clave: historia del conservacionismo mexicano, áreas naturales protegidas, parques nacionales, modelos de conservación, Miguel Ángel de Quevedo, Enrique Beltrán, Gonzalo Halffter
\end{abstract}

\begin{abstract}
The conservation of natural resources is a concern that is reflected in the international agenda. It is important to note that from the nineteenth century to today is part of the reflections of scientific communities in different latitudes. We can say that the concern for conservation has different stages depending on the value that is assigned to natural resources at different times in history. In Mexico the concern for conservation in the same way as in other countries, was present since the late eighteenth century and is currently maintained. This article aims to review the relationship between Mexican conservationism and international debates on the subject and how this concern has had different stages and materialized in what is now known as National Parks, Forest Reserves, Wildlife Sanctuaries or Biosphere Reserves. This is a small global history of a "hybrid science" and how it was expressed in what we now call Natural Protected Areas. Key Words: history of Mexican conservationism, protected natural areas, national parks, conservation models, Miguel Angel de Quevedo, Enrique Beltran, Gonzalo Halftter
\end{abstract}

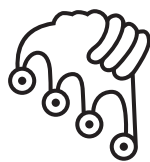

IZTAPALAPA

Agua sobre lajas

1 * Este artículo forma parte de la investigación del Proyecto papirt ia40i6I7 "Ciencias ambientales y bioética: una mirada desde la historia del conservacionista mexicano del siglo $\mathrm{xx}$ ", auspiciado por la DGAPA-UNAM. 


\section{Introducción}

En la actualidad, México es parte de un grupo de naciones catalogadas como "megadiversas". Para cumplir con esta adscripción internacional es obligatorio que se conjuguen dos variables indisolubles en el territorio: diversidad cultural y biológica. En nuestro país, la primera está representada por los pueblos indígenas que han habitado históricamente el territorio nacional y han domesticado gran diversidad de especies. La segunda la constituyen los endemismos biológicos y la gran diversidad de ecosistemas forestales, selváticos, desérticos y marinos. En distintas escalas y niveles, esta megadiversidad cumple con una gran variedad de funciones tanto a nivel social como ecosistémico y su degradación o pérdida tiene repercusiones negativas para la sociedad en su conjunto. Por ejemplo, debido a la pobreza, la violencia, los desplazamientos forzados que han vivido históricamente miles de indígenas, se han perdido importantes conocimientos tradicionales, que antes no eran valorados, sobre la biodiversidad y cómo utilizarla. Asimismo, la pérdida de bosques y selvas donde habitan muchas comunidades indígenas-campesinas se ve reflejada a escala global en fenómenos como el cambio climático y en escala local, la pérdida de este patrimonio ocasiona perturbaciones como cambios locales en el clima, alteraciones en el ciclo hidrológico o erosión de los suelos para el cultivo.

En México, desde 1917, el Estado fue adoptando una política enfocada a la conservación de los recursos naturales, y con base en esta se fueron creando paulatinamente distintas figuras jurídico-administrativas como: parques nacionales, reservas forestales, reservas de protección de la fauna, zonas de veda o reforestación, reservas de fauna silvestre y aves o reservas de la biosfera, por mencionar algunas; lugares que hoy son reconocidos por la legislación ambiental mexicana como áreas naturales protegidas. ${ }^{2}$ En las últimas décadas, en nuestro país se han desarrollado y adoptado

2 En México las áreas naturales protegidas (ANP) fueron definidas jurídicamente por primera vez en la Ley General del Equilibrio Ecológico y Protección al Ambiente de 1988 (Diario Oficial, 28/oI/1988). No obstante, en este trabajo se utilizará el término ANP 
modelos de conservación y gestión de los recursos naturales que intentan armonizar las políticas y preocupaciones nacionales con las normas y los tratados regionales e internacionales. Y la exigencia de ajustarse a los tratados multilaterales y a las políticas nacionales en materia de conservación ha generado tensiones de diversa índole entre los pobladores locales, el gobierno o empresas, lo cual ha derivado en distintos conflictos por la gobernanza y el uso de los recursos naturales. ${ }^{3}$

Por lo mencionado en los párrafos anteriores, el objetivo de este artículo es presentar algunos ejemplos de las interacciones que se han dado históricamente entre la política mexicana de conservación de la naturaleza y las preocupaciones internacionales en la materia, retomando las propuestas y los argumentos de los actores más representativos de cada periodo. Se demostrará que el conservacionismo es una preocupación de carácter internacional desde el siglo xIx y sigue presente en nuestras sociedades, por lo que debemos pensar en qué medida las normas implementadas históricamente en México se han correlacionado con esta discusión internacional. ${ }^{4}$ En las últimas décadas podemos observar de manera más clara esta

cuando se haga referencia a los ecosistemas que en distintas etapas de la historia de México se han intentado proteger jurídicamente bajo otras categorías; en otras palabras, se utiliza como término genérico.

3 La historiografía sobre las áreas naturales protegidas en el mundo nos permite comprender que estas, dependiendo el país, adquieren particularidades en su gestión, administración y categorización. Algunos ejemplos sobre los estudios de la historia de la conservación y de las áreas naturales protegidas en otras regiones del mundo son: Bennet (2016), Morton Tourner (2014), Gissibl, Höhler y Kupper (2012) y Jepson y Whittaker (2002).

4 Otros autores que han trabajado el tema son: Gómez Pompa y Dirzo, 1995; Simonian, 1999; De la Maza, I999; Melo, 2002; Castañeda Rincón, 2006; Boyer, 2012; Carabias, 2008; Wakild, 20II; Halffter et al., 20I5; González-Ocampo, Rodríguez Quiroz y Ortega-Rubio, 2015; Radding y Cañedo G., 2016. En contraste con estos trabajos que hacen una periodización basada en la historia política y en los periodos presidenciales, la que utilizo en este artículo se basa en los cambios de los modelos de conservación, los cuales han sido delineados principalmente por científicos. En este sentido, la periodización que propongo se sustenta en las continuidades y cambios de las ideas científicas y no en las coyunturas políticas. Por tal motivo para lograr percibir con mayor claridad estos procesos de continuidad y cambios, se requiere analizarlos en periodos históricos largos. Por estos motivos, es relevante señalar que ninguno de los autores señalados ha puesto énfasis en que el conservacionismo es un paradigma internacional desde el siglo XIX y por consiguiente no se han analizado las relaciones que tienen los debates en otras latitudes y cómo se han expresado en México. 
correspondencia en los tratados internacionales que el país ha firmado y ratificado en materia de conservación ambiental. Organicé el texto en tres partes, y cada una, a su vez, dará razón de los cortes históricos propuestos para comprender cómo se fueron incorporando a la política ambiental mexicana nuevas variables conservacionistas, que desde nuestro punto de vista corresponden a una "ciencia híbrida" en la cual se entrelazan los saberes de distintas comunidades, sean científicas o no (Boyer, 2018a, 2018b).

En la primera parte informo de las causas que llevaron al gobierno mexicano a incorporar, entre 1890 y 1900 , las que podríamos considerar como primeras medidas conservacionistas; posteriormente analizo las acciones adoptadas entre 1917 y la década de 1950, lapso en el que se consolida el paradigma enfocado a la conservación de la cubierta forestal en partes funcionales de las cuencas. $Y$ al final aparece el periodo de I970 a 1999, etapa en que se busca la conservación del germoplasma en ecosistemas que anteriormente no eran importantes porque no existían las tecnologías para generar riqueza a partir de los genes. Me interesa resaltar una definición de las reservas de la biosfera como modelo de cooperación multilateral. No reviso a profundidad las leyes que se han creado en materia de conservación. Los cortes temporales propuestos buscan dar un panorama analítico amplio que permita distinguir algunos rasgos de la continuidad y el cambio en los procesos y las políticas de conservación en México.

\section{La preocupación por la conservación y las primeras reservas forestales (1890-1900)}

Mientras los físicos de última generación tienen claro que no es posible conocer la causalidad inicial de los fenómenos complejos, muchos científicos sociales, incluidos los historiadores, seguimos aspirando a encontrar esa partícula que detonó la red de interacciones que fueron conformando un proceso social o histórico. Aspirar a descubrir ese pequeño corpúsculo o la causa primigenia, en nuestro caso ese o esos documentos que expliquen el origen, parece ser parte de una muy antigua aspiración de nuestro espíritu positivo. Empero, en esta parte del trabajo intentaremos alejarnos un poco de esa bella tradición y partir nuestro análisis de la siguiente pregunta: ¿Es posible saber con exactitud en qué momento de la historia se configuró la preocupación por la conservación de la naturaleza en México y con qué fenómenos se relaciona? Todo parece indicar que es poco probable que logremos encontrar una 
respuesta única; sin embargo, lo que sí podemos hacer es indagar en las causalidades que nos permitan exponer y contar con algunas explicaciones convincentes. ${ }^{5}$

Con base en los registros históricos disponibles podemos afirmar que una de las primeras preocupaciones por la destrucción de la naturaleza se dio en materia forestal, lo cual respondió a dos variables: por la carestía de materiales y energéticos para la producción, a finales del periodo colonial, y por las afectaciones que la pérdida de la cubierta forestal causaba en el clima y en la hidrología del territorio en esa misma época. Para ejemplo, retomaremos a dos autores que consideramos voces representativas del periodo señalado. La primera se puede observar en las reflexiones que José Antonio Alzate desarrolló en el proyecto sobre el descubrimiento y uso del carbón mineral y la segunda en el texto de Alexander von Humboldt intitulado Ensayo político de la Nueva España. Por la inobjetable proximidad temporal de ambos trabajos podemos sostener que la preocupación por la degradación forestal en México tiene esta doble raíz y una no excluye a la otra.

A finales del siglo xviri, el sabio José Antonio Alzate y Ramírez, a solicitud expresa del virrey Binciforte, escribió el "Proyecto del Br. José Alzate Ramírez sobre el descubrimiento y uso del carbón mineral". Y aunque dicho opúsculo no tenía la intención de exponer la pérdida de la cubierta forestal en el territorio novohispano, al abordar aspectos relacionados con los recursos energéticos necesarios para el funcionamiento del ramo minero abordó los aspectos forestales como parte de su reflexión. Señaló entonces que los europeos encontraron en la Nueva España un gran suministro de montes poblados de árboles que les proporcionaban grandes cantidades de leña y carbón para todo tipo de necesidades. El sabio Alzate explicó al virrey que:

como los montes de día en día se aniquilan, y no se verifican nuevas plantaciones de arboles, llegará el día en que los pobladores de este vasto y extenso país suspiren por combustibles, y que los mineros clamen por material para purificar plata y extraer o separar los materiales [...] Ya las maderas se les escasean, y en breve, por falta de combustible vegetal, abandonarán las minas a causa de los excesivos costos que no pueden sufragar el beneficio de la plata. [...] iQué felices serían nuestros salitreros, si consiguen el carbón mineral para sus oficinas! Por que para cada oficina se necesita un bosque, y las pailas permanecen en hervor por 48 horas (Alzate, 1988: 71, 75, 78).

5 Para una discusión sobre la causalidad y la disciplina histórica: Bloch, 1996: 27-32; Carr, I981: II7-I46 y Gaddis, 2004: 125-I46. 
A finales del siglo xvin la falta de combustible y de materiales para el funcionamiento del ramo minero y para otras actividades era una preocupación importante de la Corona. Esta problemática se fue agudizando con el transcurrir de los años y alcanzó a los gobiernos independientes del siglo XIX, sin importar su filiación monárquica, liberal o conservadora.

Hay que tomar en cuenta y no perder de vista que México nunca contó con las reservas de carbón mineral suficientes para solventar las necesidades básicas en los hogares y mucho menos para mover el proceso de industrialización que era visto como la vía que toda nación que aspirara a ser civilizada tenía que seguir y alcanzar. En este sentido, después de la segunda mitad del siglo xix toda nuestra fuerza motriz requirió el uso de grandes cantidades de carbón vegetal tanto para la minería como para los ferrocarriles y las industrias (Río de la Loza, I9II: 329-334 y 335-347; Almaraz, I865; Dublan y Lozano, 1878: 160-162).

La preocupación por la pérdida de la cubierta forestal y por sus consecuencias no sólo se entendió en clave energética o material: Alexander von Humboldt expresó lo grave que era la reducción de coeficiente boscoso en lo que todavía era la Nueva España. Utilizando el trabajo que realizó el general Andreosi para el Canal del Medio Día, explicó que la deforestación en todas partes tenía las mismas consecuencias (Humboldt, I822: 399). El sabio prusiano señaló que, debido a la falta de cubierta forestal alrededor del depósito de San Ferreol, el caudal de sus aguas había disminuido y que este mismo fenómeno se había experimentado en la provincia de Caracas, en el Lago Tacarigua, el cual se estaba desecando poco a poco a causa de los suelos desmontados de los Valles de Aragua. Presentó estas mismas observaciones para la Nueva España externando que:

Los que han recorrido la península saben cuán enemigo es el pueblo español de plantíos sobrios en las inmediaciones de las ciudades, y aun de las aldeas. Parece pues que los primeros conquistadores quisieron que el hermoso valle de Tenochtitlan se pareciese en todo al suelo castellano en lo árido y despojado de su vegetación. Desde el siglo $16^{\circ}$ se han cortado sin tino los árboles, así en el llano sobre que está sita la capital, como en los montes que la rodean. La construcción de la nueva ciudad, comenzada en 1524, consumió una inmensa cantidad de maderas de armazón y pilotaje. Entonces se destruyeron, y hoy se continúa destruyendo diariamente, sin plantar nada de nuevo [...] La falta de vegetación deja el suelo descubierto a la fuerza directa de los rayos del sol, y la humedad que no se había ya perdido en las filtraciones de la roca amigdaloide basáltica y esponjosa, se evapora rápidamente, y se disuelve 
en el aire, cuando ni las hojas de los árboles ni lo frondoso de la yerba defienden el suelo de la influencia del sol y vientos secos del medio día (Humboldt, I822: 333).

Las palabras de Humboldt son claras al señalar que, debido a la falta de cubierta forestal, disminuyeron los manantiales y la humedad de la atmósfera. Asimismo, los desmontes habían aumentado la violencia de las inundaciones en la ciudad (Humboldt, I822: 399). Humboldt concluyó que estos fenómenos no eran exclusivos de la Ciudad de México y que había "llamado mucho la atención sobre el poder de estas causas, que son las mismas en todos los climas" (Humboldt, I822: 399).

Los trabajos de Alzate y el de Humboldt muestran que a finales del siglo xviri y principios del xix la pérdida de los bosques era motivo de una doble preocupación: la escasez de energía y materiales y los cambios en la humedad, la hidrología y la erosión de los suelos. Ambos autores tenían claro que si no ocurría una intervención del ser humano, por ejemplo, con nuevas plantaciones de árboles para que este recurso no siguiera deteriorándose habría consecuencias funestas. La influencia que estos pensadores tuvieron en su momento es incuestionable para la historiografía de la ciencia; sus ideas nutrieron las reflexiones de muchas generaciones $y$, por la gran difusión que tuvieron en América Latina, podemos suponer que sus preocupaciones fueron base de muchas otras reflexiones posteriores que vieron en la destrucción de los bosques un serio problema mundial (Urquiza, 2018).

Esta preocupación estaba presente en México durante la primera mitad del siglo XIX, pero no fue hasta la segunda mitad de aquella centuria que se comenzaron a tomar medidas para hacerle frente. Pese a los constantes reclamos que se hacían desde distintos escenarios, sociedades científicas y la prensa de la época, crecían los requerimientos de energía y materiales de los sectores productivos y de la economía doméstica y, por consecuencia, la presión sobre los bosques no solo se mantenía, sino que iba en aumento, sin contar con la falta de reservas de carbón mineral. Podemos sostener, gracias a las intervenciones de Alzate y Humboldt, que las repercusiones de la explotación de los bosques iban de la mano con el incesante y acelerado proceso de industrialización en distintos países.

Las discusiones de las comunidades científicas decimonónicas conformadas por abogados, naturalistas, químicos, ingenieros, agrónomos, entre otros, sobre los perjuicios por la pérdida de las florestas incorporaron otras reflexiones. Por ejemplo, en México se discutió intensamente la relación entre propiedad y conservación y los límites que el Estado debía imponer a los particulares en el uso de los recursos forestales (Ramírez et al., I870: 14-24; Payno, I870: 77-9I). También dichas comunidades denunciaron la relación entre deforestación, cambios locales 
en el clima, modificaciones en la hidrología y erosión de los suelos, y cómo esto en conjunto afectaba la agricultura del país. En este contexto podemos exponer que la preocupación por la pérdida de los bosques estuvo presente durante todo el siglo XIX en México y en otras latitudes; fue un problema que, como expresó Humboldt, se dio en todos los climas. Esto no podía ser de otra forma porque la degradación de los bosques fue un proceso histórico que experimentaron todas las sociedades sin importar su grado de industrialización.

Los científicos mexicanos veían en la propiedad comunal y en los pueblos indígenas uno de los factores que más afectaban la conservación de los bosques. Esta perspectiva fue ampliamente aceptada durante todo el siglo xix. Por ejemplo, Leopoldo Río de la Loza expresaba que

los indígenas de los pueblos que tienen bosques propios, han cortado y cortan a su antojo los árboles, sin sujeción a la ordenanza antigua de bosques y sin observar siquiera el método que aconseja la razón en beneficio propio. [... [ La facilidad que los indígenas tienen de transitar esas serranías por veredas practicables o enteramente desconocidas, y aún la posesión de hecho en que han estado y aún permanecen de explotar a su arbitrio este ramo de la riqueza pública, han hecho nulatoria toda medida que tiende a civilizarlos en este punto y poner coto a práctica tan abusiva (Río de la Loza, I9II: 329, 333).

Esta perspectiva sobre los pueblos indígenas y la propiedad común fue respaldada por muchos de los científicos y liberales que también estaban preocupados por las terribles consecuencias de la deforestación. Sin embargo, más que argumentos basados en datos empíricos, su postura reflejaba el compromiso que tenían con un modelo basado en el fomento a la propiedad privada.

La pérdida de grandes masas forestales y sus impactos para la economía y para la "higiene pública" era un hecho aceptado por las elites científicas nacionales e internacionales. Esto se puede corroborar en el informe que presentó José Yves Limantour al gobierno mexicano, después de su participación en el Congreso Internacional de Ciencias Geográficas, celebrado en París, en 1875. Según dicho personaje, esta discusión se dio en el Quinto Grupo de Trabajo del Congreso, el cual abordó el problema de los desmontes y la devastación de los bosques. El informe señalaba que era ampliamente reconocida la influencia de los bosques para el comercio, la industria, la agricultura y la higiene. Es importante indicar que los resolutivos y acuerdos del Congreso señalaron: 
recomendar de un modo especial a los gobiernos, municipios y particulares la conservación de los bosques existentes y la formación de nuevos, como altamente provechoso bajo todos aspectos, y sobre todo para la higiene. En México, en donde la madera para construcción así como el carbón y la leña van aumentando rápidamente de precio a la vez que disminuyendo de un modo notable en su calidad; en donde no se emplean ni se empleará por algún tiempo en ciertos lugares otro combustible que no sea carbón de madera o leña, cuyo consumo constantemente tiene que estar aumentando por el desarrollo que va tomando cada día el uso de las máquinas; en México, repito no se toma ninguna providencia contra esa devastación que amenaza ser uno de nuestros mayores males económicos. [... ] y que por otra parte nunca dejará de ser la madera una materia de primera necesidad, ni los bosques una de las condiciones higiénicas de más importancia [... No se me oculta tampoco la imposibilidad de hacer efectivas en toda la extensión del territorio de la República las disposiciones legislativas sobre la materia; pero no cabe duda que si está en manos del Gobierno el evitar que los bosques sigan alejándose cada día más de las grandes poblaciones, así como por otra parte el fomentar plantío de nuevos bosques (Limantour, 1878: 27).

En esta referencia podemos observar cómo el paradigma conservacionista era discutido en los foros científicos más importantes de aquel momento. Las recomendaciones que se hacían fueron poco a poco influyendo en las medidas adoptadas en México. Es importante mencionar que en ese congreso también participó Manuel Fernández Leal, quien más tarde se desempeñaría como secretario de Fomento durante el régimen de Porfirio Díaz y sería el encargado de introducir distintos mecanismos a favor de la conservación forestal.

Fernández Leal estaba al tanto de los debates internacionales en la materia. En este sentido puede asumirse que fue sensible a la necesidad de enfrentar el problema. En I893, ya como secretario de Estado, retomó una iniciativa que, pese a no ser vinculante, tuvo un impacto en el territorio: la conmemoración del “Día del árbol”, que era parte de una tradición internacional. La difusión del proyecto era constante. La prensa publicaba referencias al respecto sin importar la sede. Por ejemplo, La Sombra de Arteaga dedicó una larga nota al que se realizó en los Estados Unidos. El texto periodístico explicaba que se había celebrado por vez primera en 1874 , en el estado de Nebraska (La Sombra de Arteaga, I896: 88). Y los medios hacían eco de la preocupación gubernamental:

Desde hace tiempo y en diversas publicaciones esta Secretaría ha venido llamado la atención de las autoridades y de los propietarios, sobre los graves perjuicios que 
están ocasionando las devastaciones de los bosques. [... Los males que se indican como probables, a consecuencia de aquellos destrozos, se van palpando de día en día, no solamente por la carestía y escasez de maderas y de combustibles para tantas industrias que los necesitan, sino aún para los más indispensables usos económicos. Por otra parte, la higiene de las poblaciones, el empobrecimiento de los manantiales, la climatología general del país, están resintiendo de un modo notable las consecuencias de aquella causa (La Sombra de Arteaga, 1893:271).

Cabe mencionar que el enfoque que se dio en el caso mexicano al "Día del árbol" incorporó los aspectos energéticos-materiales y los relacionados a la climatología, la hidrología y la higiene. En este sentido, podemos decir que desde la segunda mitad del siglo xix se configuró en el país un paradigma conservacionista basado en una perspectiva amplia de las afectaciones por la deforestación. Asimismo, podemos ir viendo en estos ejemplos la forma en que las medidas tomadas en otros países, así como las reflexiones científicas internacionales en las que participaron muchos científicos mexicanos, tuvieron influencia en las leyes y políticas adoptadas en México.

El día 26 de marzo de 1894 fue aprobada la primera medida de carácter vinculante a favor de la conservación de los bosques y quedó plasmada en los artículos 2I y 70 de la Ley sobre ocupación y enajenación de terrenos baldíos de los Estados Unidos Mexicanos. El artículo 2r estipuló que "El Ejecutivo Federal queda facultado para reservar temporalmente los terrenos baldíos que estime conveniente, para conservación o plantío de montes, reservación o reducción de indios, o colonización, en los términos que establezcan las leyes" (Secretaría de Fomento, 1913: 66). Asimismo, el artículo 70 facultaba a la Secretaría de Fomento a expedir los reglamentos para la explotación de bosques que temporalmente se reservaran. De esta Ley se derivó el "Reglamento para la Explotación de los Bosques y Terrenos Baldíos y Nacionales y permisos de caza y pesca" (Secretaría de Fomento, I913: 103-27), aprobado el i de octubre de I894 para que entrara en vigor el i de noviembre del mismo año. Hay que señalar que este reglamento también incorporó la perspectiva de la conservación desde su primer artículo; sin embargo, pese a esta legislación, los resultados fueron mínimos.

Con base en la ley del 26 de marzo de 1894 se decretaron las primeras reservas forestales de la nación. El 30 de abril de 1894 se emitió el decreto que reservaba los bosques en los distritos de Rayón, Arteaga, Andrés del Río, Iturbide, Hidalgo y Mina, en el estado de Chihuahua; el 6 de mayo de 1895, los bosques en los terrenos comprendidos en el primer paralelo de latitud llamado Santiago Chixoy y los ríos Chixoy, Usumacinta, Lacantum y Chajul, en el estado de Chiapas; en el istmo de 
Tehuantepec fueron reservados terrenos boscosos correspondientes a los estados de Tabasco, Veracruz y Oaxaca (Secretaría de Fomento, 1897: 390-392; Dublan y Esteva, I898: 267-268); el Io de mayo de 1898, en el estado de Hidalgo, el bosque de El Chico fue decretado como reserva forestal (Dublan y Esteva, 1899: 130). En términos estrictamente jurídicos, los casos antes mencionados fueron las primeras áreas naturales protegidas en México, decretadas por el gobierno de Porfirio Díaz. ${ }^{6}$

Durante la segunda mitad del siglo xix, el vínculo entre leyes y políticas a favor de la conservación forestal en México y los debates científicos internacionales podrían parecer inexistentes o poco claros. Sin embargo, la relación se explica en las acciones que se tomaron, en distintos países, incluido el nuestro, para desarrollar diversos instrumentos que ayudaran a fomentar la conservación de los bosques por la importancia que estos tenían para la economía, la climatología, la hidrología y para la higiene pública. ${ }^{7}$ En el caso mexicano, esta influencia se puede sostener gracias a las publicaciones científicas que circulaban en el país, lo que muestra el flujo de estas ideas desde finales del siglo xvir. ${ }^{8}$

\section{El modelo conservacionista posrevolucionario (1917-1950)}

Después de la aprobación de los mecanismos jurídicos y los decretos que estipularon la creación de las primeras reservas forestales nacionales, el gobierno mexicano siguió adoptando una serie de medidas que ayudaran a enfrentar los graves problemas

6 En distintos estudios se afirma que la primera anp de México fue el bosque del Desierto de los Leones, decretada por Sebastián Lerdo de Tejada en 1876. Sin embargo, ninguno hace referencia directa al decreto en cuestión. Por lo tanto, al no poder contrastar esta información con alguna fuente histórica, en este trabajo se toma como referencia la ley de 1894 y los decretos de reservas de bosque de 1894-1895.

7 Por ejemplo, en el caso de Venezuela las leyes aprobadas por Simón Bolívar, en I825 y I829 (Fundación Biblioteca Ayacucho, 2009: 258; Bolívar, 1829). Asimismo, en Brasil, la Floresta de Tujuca fue creada por el ministro de Agricultura, Manuel Felizardo de Souza, el ir de diciembre de 186I. Esta reserva tuvo el pleno consentimiento del emperador Pedro ir y el objetivo que se perseguía era la recuperación de los manantiales que abastecían de agua a la ciudad de Rio de Janeiro (Dias Leite, 1997: 388).

8 Distintas revistas decimonónicas publicaron artículos que abordaron el problema de la deforestación, la importancia que tenían las aves para la agricultura y la extinción de especies de animales por la caza indiscriminada: Boletín de la Sociedad Mexicana de Geografía y Estadística y El Progreso de México. 
que generaba la deforestación. Sin embargo, pese a estos esfuerzos se tuvieron que enfrentar otros retos, entre los que podemos mencionar: la organización de un departamento especializado que atendiera el ramo de bosques, así como la falta de cuadros especializados en la materia (Quevedo, 1909: 3-I2; La Redacción, I910: 179-208).

Entre 1900 y 19I0, representantes del gobierno mexicano participaron en distintas reuniones internacionales, como los Congresos Internacionales de Urbanismo de París 1900 y Berlín 1907, donde fueron discutidos distintos temas relacionados con la conservación de los recursos silvícolas. Ahí se fueron delineando distintas propuestas que fueron implementadas en México, principalmente durante el cardenismo, como las reservas forestales de las ciudades (Quevedo, I9II). Una de las reuniones que mayor impacto tuvieron en el desarrollo de la política conservacionista mexicana, durante la primera mitad del siglo $\mathrm{xx}$, fue la Conferencia Internacional Norteamericana sobre Conservación de Recursos Naturales, celebrada en Washington, del I8 al 24 de febrero de 1909 (Archivo Carso, 5 de febrero-20 de marzo de I909: 6).

Dicha Conferencia tuvo un carácter consultivo pero sirvió de apoyo para el desarrollo de los mecanismos adoptados en México entre 1917 y 1950. Hay que señalar que entre las delegaciones mexicana, canadiense y estadounidense se dieron muchas coincidencias en materia de conservación de los recursos naturales; sin embargo, la postura mexicana se diferenció en un aspecto sustantivo, lo cual es importante destacar, porque en esta distinción se fundamentó el modelo conservacionista mexicano durante más de 40 años. En este orden de ideas, retomamos las palabras del representante de la delegación mexicana:

Es efectivamente en México mucho más necesaria que en vuestro país y en el Canadá la conservación y mejora de los elementos forestales, porque la mayor parte de nuestro territorio, comprendida dentro de la zona intertropical, no disfruta, como los territorios más al Norte, de lluvias y otros meteoros acuosos casi permanentes, sino sólo periódicamente, con largo intervalo de sequía, bajo un régimen torrencial que hace sumamente más perjudiciales y violentos los desastrosos efectos de la deforestación, á tal extremo que, si en aquellos países del Norte el problema forestal es meramente de orden económico, en nuestro país es asunto mucho más grave, porque es también cuestión de orden biológico, vinculada como lo está muy estrechamente á las condiciones de salubridad pública, de comodidad y demás que requiere la vida animal ó la habitabilidad del país. [...] en los Estados Unidos y en el Canadá, en cuyos territorios, como antes se ha dicho, la cuestión forestal es meramente de carácter económico, significando tan sólo tener más o menos riqueza maderable 
para las necesidades actuales y futuras; $y$, por lo que esta cuestión puede afectar a la hidrología y conservación de la riqueza agrícola en mucha menor escala que en México (Quevedo, 1909b: 78, 8I).

En la "Declaración de principios" se reconocen como recursos naturales todos los elementos aprovechables para el uso humano como medios de vida y bienestar que estuvieran contenidos en la superficie del globo: suelo, agua y bosques, además de los que se encontraran en el subsuelo, como los minerales. Se declaró que: "Reconocemos que aquellos recursos, necesarios para la vida, deben considerarse de utilidad pública; que la propiedad de los mismos implica determinados deberes hacia el público, y que, en cuanto sea posible, deben adoptarse medidas eficaces para protegerlos contra todo monopolio perjudicial" (Quevedo, I909b: 99).

Años más tarde, esta perspectiva se vio reflejada en la Constitución mexicana de 1917. El artículo 27 señalaba, en su párrafo tercero, que:

La Nación tendrá en todo tiempo el derecho de imponer a la propiedad privada las modalidades que dicte el interés público, así como el de regular el aprovechamiento de los elementos naturales susceptibles (sic) de apropiación, para hacer una distribución equitativa de la riqueza pública y para cuidar de su conservación. [...] para evitar la destrucción de los elementos naturales y los daños que la propiedad pueda sufrir en perjuicio de la sociedad. (Diario Oficial, 5 febrero 1917ः 150)

Bajo estos argumentos, fueron decretándose, en distintos periodos, parques nacionales, reservas forestales, reservas forestales nacionales, reservas forestales de repoblación, zonas protectoras forestales, zonas protectoras forestales vedadas, zonas de repoblación forestal, zonas hidrológicas forestales, reservas de caza destinadas al refugio de la fauna nacional, zonas reservadas para la caza y pesca de especies animales y vegetales, zonas de refugio natural para la fauna silvestre y zonas de refugio de la fauna silvestre (Vargas Márquez y Escobar, 2000). ${ }^{9}$ Este modelo de conservación fue acompañado por una serie de políticas agrarias que también aspiraban a lograr que la cubierta forestal del territorio se conservara. ${ }^{10}$ En este sentido podemos sos-

9 En este trabajo están contenidos la mayor parte de los decretos federales sobre las ANP a lo largo del siglo $\mathrm{xx}$.

10 Después de I92I, con algunas modificaciones menores, muchos de los decretos de restitución y dotación señalaban que: "CONSIDERANDo QUINTO.- Que la existencia de los bosques y arbolados es de ingente necesidad para asegurar las mejores condiciones cli- 
tener que la política mexicana de conservación forestal postrevolucionaria se nutrió ampliamente del debate conservacionista que se desarrolló entre México, Canadá y Estados Unidos, en 1909, pero también adquirió rasgos propios, como veremos a continuación al analizar algunos decretos de conservación en materia forestal.

La primera área natural protegida en México que obtuvo la categoría de parque nacional fue el Desierto de los Leones, en 1917. Con este decreto, firmado por el presidente Carranza, inició el modelo conservacionista posrevolucionario, el cual se fundamentó en la responsabilidad que tenía el Estado, a través del Ejecutivo federal, de cuidar y fomentar los bienes nacionales, especialmente los bosques, debido a su indiscutible interés público (Boletín Oficial de la Secretaría de Fomento, 8 de noviembre de I9I7:640-64I). A este decreto le sucedieron otros que reflejan cómo el conservacionismo mexicano no siguió un modelo restrictivo; intentó incorporar distintas variables productivas, dependiendo la categoría jurídica que se le asignara al área que se quisiera conservar (Diario Oficial, 24 de abril de 1926: I05I-I055).

Si se revisan los considerandos de los distintos decretos presidenciales que dieron la categoría de parques nacionales, zonas protectoras forestales y reservas forestales nacionales a distintas áreas naturales del país se puede observar que la intención que tenían era la conservación de distintas partes funcionales de las cuencas. Lo antes mencionado buscaba mantener la estabilidad climática e hidrológica, así como evitar que los suelos se erosionaran.

matéricas y meteorológicas del país y conservar una de las principales fuentes naturales de riqueza pública; y que para dar plena satisfacción a las necesidades sociales citadas, se hace del todo punto necesaria la explotación en común de los terrenos forestales, y el exacto cumplimiento de las leyes en la materia. Por estas consideraciones y a partir de la fecha de la actual resolución, los vecinos de la ciudad de Puruándiro quedan obligados a mantener, conservar y fomentar la vegetación forestal existente en la superficie de terreno que se les concede y a explotarla en común, aplicándose el producto de dicha explotación a los servicios públicos de la comunidad, en la inteligencia de que el cultivo a que fuere susceptible el terreno de la parte arbolada del ejido deberá sujetarse a las ordenaciones que sobre el particular contenga la Ley de Bosques respectiva. CUARTo.- Se previene a los vecinos de la ciudad de Puruándiro, que a partir de la fecha de la actual resolución, quedan obligados a mantener, conservar y fomentar la vegetación existente, en la superficie de terreno que se les concede y a explotarla en común, aplicándose el producto de dicha explotación, a los servicios públicos de la comunidad, en la inteligencia de que el cultivo a que fuere susceptible el terreno de la parte arbolada del ejido, deberá sujetarse a las ordenaciones que sobre el particular contenga la Ley de Bosques respectiva" (Diario Oficial, 28 septiembre 1923: 335). 
Desde nuestro punto de vista, uno de los ejemplos más representativos está plasmado en el decreto firmado por el presidente Abelardo Rodríguez, el 3 de enero de 1934. Aquel día fueron declaradas zonas protectoras forestales los terrenos arbolados de las cuencas hidrográficas de los Sistemas Nacionales de Riego en construcción o en proyecto. En los considerandos expuestos se señaló que una de las políticas de mayor importancia para el Gobierno Federal eran los Sistemas Nacionales de Riego porque: "representan las obras de mayor costo o importancia para el desarrollo de los trabajos agrícolas de diversas regiones del país" (Diario Oficial, 3 enero 1934: 23-28).

En uno de los considerandos se puede observar que el modelo de irrigación posrevolucionario contemplaba directamente la conservación forestal de las cuencas, porque con la pérdida de los bosques, las corrientes que alimentaban los vasos de las presas disminuían y se podían generar escurrimientos torrenciales (Diario Oficial, 3 enero 1934: 23).

Como se mencionó en párrafos anteriores, estas zonas protectoras no eran restrictivas, y para ejemplificarlo es importante retomar los acuerdos tercero y cuarto:

Tercero. El Servicio Forestal, con la ayuda de las demás dependencias del Ejecutivo, autoridades locales y sociedades $u$ organizaciones particulares que estén en posibilidad de cooperar, formulará desde luego el programa general de reforestación en cada zona, para ponerlo en práctica en las regiones de las cuencas hidrológicas de los ríos y arroyos donde sea más urgente la restauración de la vegetación forestal.

Cuarto. El presente acuerdo no implica restricción alguna de los trabajos agrícolas o ganaderos siempre que no afecten terrenos cubiertos de arbolado de origen natural o artificial (Diario Oficial, 3 enero 1934: 28).

La intención de mantener y restaurar la cubierta forestal de los Sistemas Nacionales de Riego incluiría a diferentes actores, entre los que se encontraban los particulares. De esa manera, el proyecto intentó tener un alcance nacional, una conjunción del trabajo de autoridades, sectores sociales, empresariales y particulares. El acuerdo no excluyó las actividades agrícolas ni ganaderas, por lo que el conservacionismo intentó implantar un modelo incluyente en el que se siguieran desarrollando las distintas actividades productivas.

Durante la década de 1930, los trabajos de cooperación entre los gobiernos mexicano y estadounidense fueron bastante fructíferos en muchos aspectos. Durante estos diez años encontramos ejemplos de cómo la creación de áreas naturales protegidas se apoyó en el diálogo que los funcionarios mexicanos mantenían con los 
expertos de Estados Unidos. Por ejemplo, entre 1935 y 1936 se realizaron varias reuniones bilaterales en las que se discutieron los pasos para la creación de una Comisión Internacional de Parques. En estos encuentros se acordaron medidas como la creación de parques nacionales, reservas forestales y refugios de la fauna a lo largo de la frontera. Muchas de estas propuestas no se concretaron, pero otras sí dieron resultados.

Sin lugar a dudas, uno de los casos más ilustrativos fue la firma del Tratado para la Protección de Aves Migratorias y Mamíferos Cinegéticos firmado por Estados Unidos y México en $1936 .{ }^{11} \mathrm{El}$ acuerdo señalaba de manera clara la importancia de la cooperación binacional y que:

Considerando que algunas de las aves llamadas migratorias, en sus viajes cruzan los Estados Unidos Mexicanos y los Estados Unidos de América, en cuyos países temporalmente habita; Considerando que es justo y conveniente proteger dichas aves migratorias, cualquiera que sea su origen en los Estados Unidos Mexicanos y en los Estados Unidos de Norte América para que no se extingan sus especies; Considerando que para el fin indicado es necesario emplear métodos adecuados que permitan utilizar racionalmente las aves migratorias tanto en el deporte cuanto para alimentación, el comercio y la industria; Los gobiernos de ambos países han convenido en formalizar una Convención que satisfaga la necesidad apuntada (Diario Oficial, I5 mayo 1937: 2).

Asimismo, el tratado indicó que se determinarían zonas de refugio en las que estaría prohibida la captura de dichas aves. Es importante señalar que México decretó reservas de la fauna desde 1928, y que la primera de estas intentó proteger a la foca que habitaba en la isla de Guadalupe y que las subsecuentes se ubicaron principalmente en los estados del norte del país. Para un trabajo sobre las reservas de la fauna en aquel periodo, puede revisarse Vargas Palestina, 2019.

México desarrolló mecanismos propios y muy importantes. En este contexto se decretaron vedas, tanto en explotación forestal como en especies animales (Zinser, 1940: 50-52). En 1935 se aprobó el acuerdo que señalaba:

11 Esta preocupación también se incluyó en el vir punto de acuerdo de la Conferencia de Washington de 1909: "Reconocemos que la preservación de los animales silvestres de caza está íntimamente relacionada con la conservación de los recursos naturales. Por consiguiente, favorecemos la reglamentación de la caza, la creación de zonas de reserva para animales de caza y la protección especial de los pájaros y otros animales que sean útiles para la agricultura" (La Redacción, 1909: 107). 
Habiéndose introducido en aguas interiores del país, sin la debida precaución y estudio, especies exóticas de animales y vegetales, como la llamada trucha y carpa en el Lago de Pátzcuaro y el Lirio en Chapala, se han determinado daños tan graves como la progresiva desaparición del pescado blanco, tan valioso y estimado, y perjuicios como el entorpecimiento de la navegación [... I I - Queda prohibido, sin la autorización expresa de este Departamento Forestal de Caza y Pesca, la introducción en aguas interiores de la República, de cualquier especie animal o vegetal exótica (Boletín del Departamento Forestal y de Caza y Pesca, 1935-1936: 82-83).

Consideramos que esta medida adoptada por el gobierno mexicano, aunque se refiera a la introducción de especies en aguas interiores, puede ser uno de los antecedentes del "Convenio de Diversidad Biológica" firmado y ratificado por varios países, incluido el nuestro, después de la Conferencia de Río en 1992, en cuyo artículo $8^{\circ}$, inciso b) se expone que: "Impedirá que se introduzcan y controlará o erradicará las especies exóticas que amenacen a ecosistemas, hábitats o especies" (onU, 1992: 7).

La política de conservación impulsada desde el gobierno federal trajo consigo conflictos por el uso de los bosques, los cuales se reflejaban directamente en los reclamos que muchos líderes ejidales hacían por las restricciones legales para la explotación de los bosques (AGN, Lázaro Cárdenas del Río, caja 362, caja 557, caja 558). Esto no era nuevo y uno de los ejemplos más claros fue el discurso que Luis Cabrera pronunció en $1912 .{ }^{12}$

12 Estas fueron las palabras de Cabrera: "Pero admitamos, Señores diputados. Estamos tan lejos de entender el problema, que en la actualidad aun los pueblos que conservan sus ejidos tienen prohibición oficial de utilizarlos. Pueblos del Distrito Federal que conservan sus ejidos a pesar de la titulación y repartición que de ellos se ha hecho, se ven imposibilitados de usarlos, bajo la amenaza de verdaderas y severísimas penas. Conozco casos de procesos iniciados contra cientos de individuos por el delito de cortar leña en bosques muy suyos, y un alto empleado de Fomento opina que los pueblos de Milpa Alta, de Tlalpan y de San Ángel, que se encuentran en las cercanías del Ajusco y que fueron los que me eligieron para diputado y que acuden a mí, naturalmente, en demanda de ayuda en muchas ocasiones, todos estos pueblos, debían suspender los cortes de leña de sus propios terrenos y entrar en orden. 'Entrar en orden' significa para él buscar trabajo por jornal, para subsistir sin necesidad de otras ayudas; es decir, bajar a tres o cuatro leguas, a Chalco, a Tlalpan o a la Ciudad de México y volver a dormir al lugar donde se encuentran sus habitaciones. Esos pueblos no debían explotar sus bosques, porque la conservación de estos es necesaria para la conservación de los manantiales que abastecen de agua potable a México. Y cuando yo llamaba la atención de la Secretaría de Fomento sobre lo imperioso de las necesidades, sobre la injusticia de la prohibición y 
Durante la administración del general Lázaro Cárdenas los esfuerzos conservacionistas vivieron una época sin precedentes. Por ejemplo, de 1917 a 1926 se decretaron nueve reservas forestales, incluido un parque nacional; de 1927 a 1934 se sumaron otras 15 , y entre 1935 y 1940 fueron incorporadas 84 más, lo que suma un total de 108 reservas forestales de la nación, donde estaba incluida la categoría de parque nacional; lo más significativo es que tan solo en el periodo cardenista se triplicó su número. Este impulso que recibió la conservación, desde mi punto de vista, se explica en primer lugar por el interés que Lázaro Cárdenas tenía en poner en marcha un proyecto de estas características y, en segundo lugar, porque el encargado de desarrollar esta política fue el ingeniero Miguel Ángel de Quevedo, quien se desempeñó como director del Departamento Forestal de Caza y Pesca durante el sexenio cardenista.

En los ejemplos que hemos retomado se puede observar cómo México intentó desarrollar un modelo de conservación que respondiera a los problemas del país. También advertir que las medidas se retroalimentaron gracias a las políticas de cooperación y a los debates científicos que mantuvieron tanto el gobierno mexicano como organizaciones civiles en el periodo 1920-1940. ${ }^{13}$ Asimismo, se confirma que la preocupación por la conservación de la naturaleza no es una singularidad histórica de ningún país, pues tal como lo señalara Humboldt: los avatares que provoca la deforestación se presentan en todos los climas. En este sentido podemos afirmar que las medidas a favor de la conservación en nuestro país adoptadas en el periodo de ig17I940 incluyeron trabajos gubernamentales internos y de cooperación internacional, así como acciones de organizaciones civiles como la Sociedad Forestal Mexicana. Para utilizar un concepto contemporáneo, se intentaba desarrollar un modelo de gobernanza ambiental basado en el conservacionismo como "ciencia híbrida".

sobre que, para los pueblos de la serranía del Ajusco está más lejos la ciudad de México que los campos zapatistas de Jalatlalco, de Santa María y de Huitzilac, y que les es más sencillo ganarse la vida del otro lado del Ajusco con el filo, que de este lado con el azadón" (Cabrera, 1985: 38).

${ }^{13}$ En 1924 la Sociedad Forestal Mexicana comisionó a un representante para participar en el Tercer Congreso Científico Panamericano. En aquella reunión celebrada en la ciudad de Lima, el delegado mexicano advirtió sobre la importancia para la conservación en la región, como en otras partes del mundo, de la declaración de principios de la Conferencia Norteamericana de Conservación de los Recursos Naturales de 1909 (Quevedo, 1925: 62). 


\section{La ecología y la conservación global de la naturaleza (1970- 1999)}

Entre 1940 y 1970 el gobierno mexicano siguió decretando áreas naturales protegidas; empero, si comparamos el número de las que fueron creadas en esos 30 años y lo contrastamos con las que se establecieron durante el cardenismo, podemos sostener que el impulso a esta política fue deficitario (Castañeda Rincón, 2006; Simonian, 1999: 137-158). Asimismo, si analizamos los considerandos que justificaron su creación podemos notar que se le dio continuidad al interés de conservar principalmente los bosques y algunas especies de fauna silvestre.

Es importante puntualizar que las políticas conservacionistas en México y en Estados Unidos fueron menos dinámicas durante la segunda guerra mundial (Boyer, 2012-2013). Sin embargo, al finalizar el conflicto armado se abrió una coyuntura que fomentó la cooperación internacional en materia de conservación. Fue después de I949 cuando se asumió por primera vez la conservación de la naturaleza como una agenda global y no solamente nacional o regional. Lo dicho se ve reflejado en la Conferencia Científica de las Naciones Unidas sobre la utilización y conservación de recursos naturales, en la cual se hizo una división de seis ejes temáticos: suelos, agua, bosques, combustible y energía, minerales y animales silvestres y acuáticos (ONU, 1950: XI).

A partir de la década de 1960 fueron apareciendo nuevos retos globales en materia de conservación del medio ambiente: el crecimiento poblacional, las afecciones por la lluvia ácida, la crisis energética del petróleo, la contaminación a gran escala de productos químicos como el DDT, la disminución de la capa de ozono, el calentamiento global del planeta y la pérdida de la biodiversidad. Estas problemáticas para el desarrollo se incorporaron tanto en las investigaciones científicas como en las agendas políticas nacionales y multilaterales.

En México, después de la década de 1970 fueron los biólogos y ecólogos los principales promotores de las políticas de conservación de la naturaleza. Su trabajo se dio en distintos niveles: instituciones educativas, agencias gubernamentales, asociaciones civiles y agencias internacionales. Sin embargo, hay que aclarar que la ecología como disciplina no siempre fue la ciencia de la conservación de la naturaleza y el conservacionismo tiene distintas raíces históricas. En el estudio de Bowler se sostiene que:

Es preciso actuar con cautela al evaluar el nacimiento de la ecología a la vuelta del siglo. En la época actual acostumbramos asociar la palabra "ecología" con la pre- 
ocupación por el medio. [...] Hubo biólogos que vieron en la ecología la ciencia que ayudaría a apoyar la explotación del medio [... L La historia muestra que tales estudios pueden emprenderse dentro de toda una variedad de sistemas de valores. Muchos de los primeros ecologistas pensaron que sus estudios alentarían un modo de explotación más científico. [...] En su forma primera, la ecología estuvo influida por el vinculo tradicional entre la ciencia y la suposición de que la naturaleza era un sistema pasivo creado para que la humanidad lo aprovechara a beneficio propio (Bowler, 1998: 224).

En 1946 se publicó en la colección Biblioteca Enciclopédica Popular el texto Los recursos naturales de México y su conservación, de Enrique Beltrán, biólogo mexicano que se convertiría, con el transcurrir de los años, en una de las figuras más importantes de la conservación a nivel mundial. En 1949 apareció un volumen intitulado La protección de la naturaleza, del mismo doctor Beltrán, quien afirmó que:

De las muchas contribuciones que los estudios ecológicos han brindado, hay una más simple pero a la vez la más interesante de todas, que es menester tener en cuenta constantemente y que, quizá por su amplitud misma, es frecuentemente olvidada: nos referimos a la noción de que todos los seres vivientes están relacionados entre sí, directa o indirectamente, $y$ que todas las modificaciones del medio físico, aunque en ocasiones parezcan muy lejanas y desconectadas, les afectan de una u otra manera. Esta fundamental noción ecológica ha sido de enorme importancia no solo esclareciendo el estudio de algunos problemas, sino también orientando las actividades humanas en el interesante y vital campo de la conservación de los recursos naturales (Beltrán, 1949).

Estos trabajos de Beltrán son una prueba contundente de que en México, antes de iniciar la segunda mitad del siglo xx, pese a no estar institucionalizada la ecología como disciplina científica, como lo estaba en otros países, la perspectiva que tenían los biólogos mexicanos, que años más tarde formarían los primeros institutos de ecología en el país, era la de una ciencia a favor de la conservación. Lo antes mencionado marca un punto importante para la ciencia ecológica mexicana porque, pese a su emergencia tardía, nació con fundamentos de última generación.

En 1962, en Seattle, se llevó a cabo la primera Conferencia Mundial de Parques Nacionales. Esta reunión marcó un punto de inflexión en la política nacional e internacional con respecto a la conservación de las hoy llamadas áreas naturales protegidas porque se llegó a diversos acuerdos, entre los cuales podemos mencionar 
la extensión mínima que debían tener los parques nacionales. Eso tuvo un impacto directo en México debido a que varios de los que se crearon durante el cardenismo no cumplían con estos requisitos y perdieron su categoría jurídica (Beltrán, 1961: v).

En Seattle, en 1962, una de las discusiones sin duda más importantes que se dio para el modelo de conservación internacional fue propuesto por Enrique Beltrán. El funcionario mexicano ${ }^{14}$ planteó que el conflicto entre preservar y utilizar la naturaleza podría ser resuelto con el desarrollo de un modelo de zonificación en las ANP (Beltrán, 1962: 38). En ese tenor, el biólogo mexicano propuso que las reservas naturales fueran ordenadas bajo el siguiente esquema: en la primera zona se permitiría albergar hoteles, restaurantes y espacios de recreo; en la segunda estaría permitida la entrada a turistas y no se permitiría la construcción de ningún tipo de infraestructura, ni siquiera caminos; en la última zona solamente estarían permitidos los trabajos de investigación de los expertos (Beltrán, 1962: 38). En la década de 1960, pese al liderazgo internacional que ya tenía Beltrán en la materia, la política mexicana a favor de la conservación de la naturaleza seguía manteniendo un ritmo deficitario. En aquellos años solamente se decretaron cuatro ANP: dos parques nacionales, una zona de refugio natural y de la fauna silvestre y una zona de reserva natural y refugio de aves.

El 24 de diciembre de 1968 la foto de la tierra tomada desde la nave Apolo 8 dejaba ver la belleza de nuestro planeta, pero también mostraba un rostro preocupante: la fragilidad en la que nos encontrábamos como especie. Muchos científicos consideran esta imagen como un detonante o la precursora de importantes reflexiones ambientales. Muchos argumentan que, por primera vez en la historia de la humanidad, comprendimos que vivíamos en un planeta con recursos limitados y finitos (Worster, 2008: II).

En junio de 1972, en Estocolmo, se llevó a cabo la Conferencia de Naciones Unidas sobre el Medio Humano. Esa cumbre marcó un antes y un después en materia de conservación internacional de los recursos naturales. En la proclama número siete se exponía claramente que:

También se requiere la cooperación internacional con el objetivo de allegar recursos que ayuden a los países en desarrollo a cumplir su cometido en esta esfera. $Y$ hay un número cada vez mayor de problemas relativos al medio que, por ser de alcance regional o mundial o por repercutir en el ámbito internacional común, requeriría una

${ }^{14}$ Es importante destacar que Enrique Beltrán se desempeñó en el gobierno federal como subsecretario Forestal y de la Fauna entre 1958 y 1964. 
amplia colaboración entre las naciones y la adopción de medidas para las organizaciones internacionales en interés de todos. La Conferencia encarece a los gobiernos y a los pueblos que aúnen sus esfuerzos para preservar y mejorar el medio humano en beneficio del hombre y su prosperidad (onU, 1973:4).

Asimismo, el principio 2 indicaba que: "Los recursos naturales de la Tierra, incluidos el aire, el agua, la tierra, la flora y la fauna y especialmente muestras representativas de los ecosistemas naturales, deben preservarse en beneficio de las generaciones presentes y futuras mediante una cuidadosa planificación u ordenación, según convenga" (ONU, I973:4).

La Conferencia tuvo resultados de importancia indudable. Uno de ellos fue la creación, en 1972, del Programa de Naciones Unidas para el Medio Ambiente (PNUMA). Cabe puntualizar que por primera vez la onu, desde que inició trabajos enfocados a la conservación del medio ambiente, contaba con una oficina dedicada exclusivamente a perseguir objetivos en ese sentido. ${ }^{15}$

Hay que señalar que estos principios relacionados con la conservación de las áreas naturales representativas, aprobados por la Conferencia de Estocolmo, tienen sus orígenes en términos de cooperación y diálogo multilateral en la Conferencia Internacional de la Biosfera, celebrada en la ciudad de París, en septiembre de 1968. En ese encuentro se promovió decididamente que la onu llevara a cabo una reunión internacional para abordar los problemas ambientales. Asimismo, se derivó, por iniciativa de la UnESCO, el programa El hombre y la biosfera. Se planteó un proyecto multilateral que daría inicio en I97 I y entre cuyos puntos relevantes estaba el reconocimiento del impacto de las acciones humanas sobre el paisaje en todo el planeta, y que la desigualdad era uno de los mayores problemas para la conservación, porque las personas estaban obligadas a utilizar los recursos que el medio les proporcionaba.

La ONU marcó como uno de los objetivos del citado programa que el ser humano tuviera una relación más armónica y respetuosa con el medio y desarrollar mecanismos económicos y técnicos que tuvieran menos impacto sobre los ecosistemas. El modelo de conservación que se propuso para alcanzar ese propósito fueron las

15 Es importante explicar que los temas sobre conservación y medio ambiente que organizó la onu estaban en el marco de la UNESCO, después de la Conferencia de Estocolmo el PNUMA fue la oficina responsable de esta materia. Por ejemplo, en la reunión que celebró la UNESCo en Fontainebleau, en 1948, se tomó la decisión de formalizar la creación de la International Union for the Conservation (IUCN) (Behrman, 1974: 2I). 
reservas de la biosfera, y fue el primero que se replicó a escala global y que emergió de las reuniones multilaterales.

En México, la década de 1970 fue importante porque se tomaron acciones más decididas en materia de conservación. En este periodo se vio reflejado, en los decretos de creación de ANP, la implantación del modelo de reservas de la biosfera. En el periodo 1970-1980 se decretaron distintos tipos de categorías de conservación como: zona de refugio de ballenas y ballenatos, zona de protección forestal y de la fauna silvestre, parques nacionales, zona de reserva y refugio de aves migratorias y fauna silvestre, por mencionar algunas. En total se decretaron en ese lapso $22 \mathrm{ANP}$, de las cuales tres fueron reservas integrales de la biosfera: Montes Azules, La Michilía y Mapimí. Cabe agregar que las reservas decretadas en este periodo formaban parte o eran complementarias de otro tipo de categorías, por ejemplo, la zona de protección forestal y reserva integral de la biosfera de la Michilía.

Uno de los actores más importantes para el establecimiento de las primeras reservas de la biosfera en México fue Gonzalo Halffter, ${ }^{16}$ quien también era uno de los principales críticos del modelo de parques nacionales. En la década de 1980 Halffter señaló que los parques nacionales eran un modelo exitoso en los países desarrollados, pero no en los que estaban en vías de serlo, pues según su argumentación había otros ecosistemas con alto valor biológico que debían protegerse (Halffter, 1984: 452-453). El modelo de la biosfera era la respuesta a una etapa histórica en que la ecología ya había monopolizado el discurso de la conservación. De ese modo, las opiniones de Halffter relacionadas con la propuesta de parques nacionales, que no fomentaba la investigación ni la conservación de los recursos genéticos, desde nuestro punto de vista se basó en un análisis que no consideró que los modelos responden a las necesidades de su época.

Uno de los aportes más importantes de Halffter al programa de reservas de la biosfera fue la inclusión de pobladores en la gestión de los espacios naturales que se pretendía conservar (Halffter, 1980ः 4). Esto marcó un nuevo modelo de conservación en México y en otras latitudes, con tal impacto que la unesco ha reconocido en esta propuesta "la modalidad mexicana" (Galante Patiño, 200I: 176). Ahora solo retomaremos algunos ejemplos de los considerandos y artículos con los que se justificó la creación de la primera reserva de la biosfera:

${ }^{16}$ Gonzalo Halffter se desempeñó como presidente del Consejo Internacional del Programa мав en dos ocasiones: 1984-1986 y 2004-2006 (Sanz y Tejeda, 2016: "Iconografía"). 
Que dentro de esta política de conservación se comprende la investigación, diseño y ejecución de todas aquellas formas de explotación y uso de los recursos naturales que benefician a un máximo de habitantes del área, asegurando la permanencia del recurso o incrementándolo.

Que el Gobierno Federal es signatario de acuerdos internacionales para la protección de los recursos naturales y la creación de una red de reservas de la biosfera, como es el programa Hombre y Biosfera (МАB) de Unesco, entre cuyos objetivos está la conservación y estudio de los ecosistemas naturales.

ARTíCulo séptimo. La reserva integral de la biosfera Montes Azules se incorporará al sistema internacional de reservas de la biosfera coordinado por la UNESCO, dando todas las facilidades necesarias para la investigación científica y tecnológica (Diario Oficial, I2 enero 1978: 7-8).

En los distintos decretos de creación de reservas de la biosfera se incluyen este tipo de considerandos, que hacen énfasis en la incorporación de las comunidades locales en la gestión de estas ANP. En el número de reservas de la biosfera que se crearon se observa claramente cómo el gobierno mexicano ratificó su compromiso con el programa de El hombre y la biosfera. ${ }^{17}$ Podemos decir que de 1978 a 1999 se decretaron 26 reservas de la biosfera, siendo este modelo al que mayor peso se le ha dado en las últimas décadas. Asimismo, se decretaron otras 56 áreas naturales con distintas categorías como: parques nacionales, reservas forestales, refugios para ballenas, por mencionar algunos. Con esto se puede sostener que el gobierno dinamizó de nueva cuenta la creación de ANP y las políticas conservacionistas.

Actualmente se han venido desarrollando nuevos modelos de conservación en México. Estos esquemas han incorporado valores y perspectivas que hace cinco décadas no habrían sido compatibles con los paradigmas conservacionistas. Podemos destacar dos que actualmente se están adoptando. En primer lugar, los geoparques, los cuales también están reconocidos por la onU y las Áreas de Protección Voluntaria-Comunitaria. Estos modelos de conservación proponen incorporar integralmente a las comunidades locales que han habitado históricamente los territorios. En

17 Como señalan Sanz y Tejeda (20I6: "Iconografía") La reserva de la biosfera Mapimí y la reserva de la biosfera La Michilía, ambas del estado de Durango, fueron las primeras reservas latinoamericanas en ser inscritas dentro de la Red Mundial de Reservas de la Biosfera de la UNESCO, como parte del programa MAB. 
este sentido podemos afirmar que la participación comunitaria, desde los debates realizados en Sevilla (UNESCo, 1996), incorporó un enfoque que apuesta por desarrollar mecanismos desde abajo.

\section{Conclusiones}

El análisis histórico basado en una periodización que utiliza el cambio en los paradigmas científicos sobre la conservación de la naturaleza nos permite demostrar que las políticas implantadas desde el Estado por los gobiernos en turno han sido una preocupación internacional, desde el siglo XIX, la cual tiene continuidades y rupturas. Asimismo, que las perspectivas sobre lo que es importante conservar está determinado por los valores y las perspectivas del discurso científico de cada época histórica, que han cambiado con el transcurrir de los años y lo seguirán haciendo, y que por lo tanto no podemos hablar de una sola perspectiva conservacionista.

La historia del conservacionismo mexicano requiere una periodización sustentada en el análisis del cambio de valores asignados a la naturaleza; una historia de las ideas sobre la conservación. Podemos señalar brevemente y de manera general que en México se han experimentado tres etapas o perspectivas conservacionistas. La primera estuvo enfocada en desarrollar mecanismos para la conservación de los bosques por la importancia que tenían como fuente de energía y materiales, en la regulación del clima y la hidrología y para evitar la erosión de los suelos. En esta etapa las comunidades indígenas eran consideradas uno de los principales problemas para la conservación forestal. En la segunda etapa se consolidó este paradigma y se ubicaron como áreas prioritarias las partes altas de las cuencas. Hay un cambio importante y se intenta incorporar a las comunidades indígenas-campesinas a la conservación forestal vía los decretos agrarios y posteriormente las cooperativas forestales, pero siempre desde la tutoría del Estado. En la tercera etapa se desarrollaron los mecanismos de zonificación y se incorporó a los actores locales en los procesos de tomas de decisiones. Asimismo, desde el siglo xix se han mantenido categorizaciones y se han sumado otras, y ninguna es excluyente. Lo que sí cambió de manera definitiva fue el modelo en que se deben gestionar. Es importante para la conservación de los ecosistemas mexicanos impulsar estudios de historia ambiental de las áreas naturales protegidas, pero estas historias ambientales de carácter local siempre deben considerar la escala global porque, como se pudo demostrar gracias a distintos ejemplos, el conservacionismo es una preocupación que se ha dado en todos los climas, desde el siglo xix. En otras palabras, la conservación, en un primer 
momento, se enfocó a intentar proteger las reservas energéticas-materiales y se perfiló a un modelo para resguardar los bancos de genes y los ecosistemas prioritarios.

\section{Archivos consultados}

Archivo Carso, fondo cDliv, carpeta 20, legajo 6I, México 5 de febrero a 20 de marzo de I909, f. 6 .

Archivo General de la Nación, Lázaro Cárdenas del Río, cajas 362, 557 y 558.

\section{Bibliografía}

Almaraz, Ramón

I865 Memorias de los trabajos ejecutados por la Comisión Cientifica de Pachuca en el año de 1864, México, Imprenta de J. M. Andrade y F. Escalante.

Alzate y Ramírez, José Antonio

1998 Proyecto del Br. José Alzate Ramírez sobre el descubrimiento y uso del carbón mineral (transcripción), México, Cuadernos de Quipu.

Behrman, Daniel

I974 En asociación con la naturaleza. La Unesco y el medio ambiente, París, UNESCO.

Beltrán Enrique

1949 La protección de la naturaleza: principios y problemas, México, Secretaría de Educación Pública.

Beltrán, Enrique

1962 "Use and Conservations: Two Conflicting Principles", en Alexander B. Adams (ed.), First World Conference on National Parks, Washington, Department of the Interior-National Parks Service, pp. 35-42.

Beltrán, Enrique

196I “Introducción”, en Ambrosio González y Víctor Manuel Sánchez L., Los parques nacionales de México. Situación y problemas, México, Ediciones del Instituto Mexicano de Recursos Naturales Renovables, pp. I-VII. Bennet, Brett

2016 Plantations and Protected Areas: A Global History of Forest Management, Cambridge, ma, міт Press. 
Bloch, Marc

1996 Introducción a la historia, México, Fondo de Cultura Económica.

Bowler, Peter

2000 Historia fontana de las ciencias ambientales, México, Fondo de Cultura Económica.

Boyer, Christopher

2012 "The Cycles of Mexican Environmental History", en Christopher Boyer (ed.), A Land Between Waters. Environmental Histories of Modern Mexico, Tucson, University of Arizona Press, pp. I-22.

Boyer, Christopher

2012-2013 "La Segunda Guerra Mundial y la «crisis de producción» en los bosques mexicanos", Historia Ambiental Latinoamericana y Caribeña, 2(I), septiembre 2012-febrero 2013, pp. 7-23.

Boyer, Christopher

2018a "La gran aceleración y el aprovechamiento forestal en la Segunda Guerra Mundial", ponencia al Seminario Interno de Investigación del Centro de Investigaciones sobre América Latina y el Caribe, UNAM, 26 de febrero de 2018.

Boyer, Christopher

$2018 \mathrm{~b}$ "Los retos de la historia ambiental mexicana y cómo repensar la historiografía mexicana”, ponencia al Seminario Bimensual «Lo común, lo privado, lo público. Dinámicas de los derechos de propiedad en México y América Central, siglos XIX-XX», I8 de mayo de 2018, organizada por Laboratorio Mixto Internacional meso y la Línea: «Nación, Estado y Pueblos Indígenas, siglos XIX-XxI» del Posgrado en Antropología Social del ciesas, Unidad Ciudad de México.

Cabrera, Luis

I985 "Discurso de Luis Cabrera -2 de diciembre de 1912-", en Expedición de la Ley Agraria. 6 de enero de 1915, México, Comisión Nacional para las Celebraciones del 175 Aniversario de la Independencia Nacional y 75 Aniversario de la Revolución Mexicana-Inehrm, pp. 17-47.

Cañedo Gamboa, Sergio A. y Cynthia Radding (coords.)

2016 Historia, medio ambiente y áreas naturales protegidas en el centro-norte de México. Contribuciones para la ambientalización de la bistoriografía mexicana, siglos XVIII-XXI, San Luis Potosí, El Colegio de San Luis. 
Carabias, Julia, Javier de la Maza y Enrique Provencio

2008 "Evolución de enfoques y tendencias en torno a la conservación y el uso de la biodiversidad", en conabio, Capital natural de México, vol. III, México, pp. 29-42.

Carr, Edward Hallett.

198I ¿Qué es la historia?, México, Planeta-Seix Barral.

Castañeda Rincón, Javier

2006 "Las áreas naturales protegidas de México; de su origen precoz a su consolidación tardía", en Scripta Nova. Revista electrónica de geografía y ciencias sociales, IO(2I8), I de agosto. Disponible en http://www.ub.edu/ geocrit/sn/sn-218-13.htm (consulta: 14/05/2018).

De la Maza, Roberto

1999 "Una historia de las áreas naturales protegidas en México", Gaceta Ecológica. Ine-Semarnap, México, 5I, nueva época, pp. 15-34.

Dias Leite, Antonio

I997 A energía do Brasil, Río de Janeiro, Editorial Nova Fronteira.

Gómez-Pompa, Arturo y Rodolfo Dirzo

I995 "Análisis histórico y perspectivas de las áreas naturales protegidas de México", Revista Universidad de Guadalajara, marzo-abril, pp. 17-2I.

Gaddis, John Lewis

2002 El paisaje de la bistoria. Cómo los historiadores representan el pasado, Barcelona, Anagrama.

Galante Patiño, Eduardo

200I "Gonzalo Halffter, 50 años de investigación en Biología", Boletín de la Sociedad Entomológica Aragonesa, 28, abril, pp. 175-18I.

Gissibl, Bernhard, Sabine Höhler y Patrick Kupper (eds.)

2012 Civilizing Nature: National Parks in Global Historical Perspective, Nueva York-Oxford, Berghahn Books.

Halffter, Gonzalo

1980 “Biosphere Reserves: A New Method of Nature Protection”, en: Peter F. Folliott y Gonzalo Halffter (coords.), en Social an Environmental Consequences of Natural Resources Policies with Special Emphasis on Biosphere Reserves. Proceedings of the International Seminar. April 8-13, 1980, Durango, México, Colorado, Rocky Mountain Forest and Range Experiment Station-Forest Service U.S.-Department of Agriculture, pp. 3-6. 


\section{Halffter, Gonzalo}

I984 “Biosphere Reserves: The Conservation of Nature for Man”, Conservation, Science, and Society. Contribution to the First International Biosphere Reserve Congress, Minsk, Byelorussia, ussR, 26 de septiembre-2 de octubre, 1983, París, unesco-United Nations Environmental Programme, pp. 450-467.

Halffter, Gonzalo, Clara Tinoco-Ojanguren, Luis Ignacio Iñiguez-Dávalos y Alfredo Ortega-Rubio

2015 "La investigación científica y las Áreas naturales Protegidas en México: una relación exitosa”, en: Alfredo Ortega-Rubio, Manuel Jesús Punkus-Rendón e Irma Cristina Espitia-Moreno [eds.], Las áreas naturales protegidas y la investigación científica en México, México, Centro de Investigaciones Biológicas del Noroeste S. C.-Universidad Autónoma de Yucatán-Universidad Michoacana de San Nicolás de Hidalgo, pp. 3-I8.

Humboldt, Alexander von

I822 Ensayo político sobre el Reino de la Nueva España, tomos I-III, París, Imprenta de J. Smith.

Jepson, Paul y Robert J. Whittaker

2002 "Histories of Protected Areas: Internationalisation of Conservationist Values and their Adoption in the Netherlands Indies (Indonesia)", Environment and History, 8, pp. I29-I72. DoI:

http://dx.doi.org/I0.3197/096734002129342620

La Redacción

1909 "Resoluciones de la Conferencia", Revista Forestal Mexicana, I(5), noviembre, pp. 98-108.

La Redacción

I9I0 "La Escuela Forestal de Guardas", Revista Forestal Mexicana, I(9), marzo, pp. 179-208.

Limantour, José Yves

I878 "Noticia sobre el Congreso internacional de ciencias geográficas" [1875], Boletin de la Sociedad de Geografía y Estadística de la República Mexicana, $3^{a}$ época, t. IV (correspondiente al año de 1878), México, Imprenta de Francisco Díaz de León, pp. 12-37.

Melo Gallegos, Carlos

2002 Áreas Naturales Protegidas de México en el siglo xx, México, UnAm-Instituto de Geografía. 
Morton Tourner, James

2014 "Rethinking American Exceptionalism. Towards a Transnational History of National Parks, Wilderness, and Protected Areas", en Andrew C. Isenberg (ed.), The Oxford Handbook of Environmental History, Oxford, Oxford University Press, pp. 282-308.

ONU

1950 Proceedings of the United Scientific Conference on the Conservation and Utilization of Resources. 17 August-6 September 1949, Lake Success, New York, Volume I, Plenary Meetings, Nueva York, United Nations-Department of Economic Affairs.

ONU

1973 Informe de la Conferencia de las Naciones Unidas sobre el Medio Humano. Estocolmo, 5 a 16 de junio de 1972, Nueva York: ONU.

ONU

1992 Convenio de Diversidad Biológica, disponible en: https;//www.cbd.int/ Payno, Manuel doc/legal/cbd-es.pdf (consulta: 05/05/2017).

I870 "Bosques y arbolados", Boletín de la Sociedad Mexicana de Geografía y

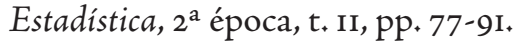

Quevedo, Miguel Ángel de

I909a "La Junta Central de Bosques", Revista Forestal Mexicana, I(I), julio, pp. 3-I2. Quevedo, Miguel Ángel de

I909b "Informe del Delegado del gobierno mexicano para tratar en la Conferencia de Washington los asuntos referentes á la conservación de los elementos forestales, presentado al honorable Sr. Gifford Pinchot, Presidente de dicha Conferencia", Revista Forestal Mexicana, I(4), octubre, pp. 77-85.

Quevedo, Miguel Ángel de

I9II Espacios Libres y Reservas Forestales de las Ciudades. Su adaptación á Jardines, Parques y Lugares de Juego. Aplicación a la Ciudad de México, México, Gomar y Busson.

Quevedo, Miguel Ángel de

1925 "La conveniencia de una acción conjunta Panamericana para la conservación de los recursos forestales del Continente", México Forestal, tomo III, núm. 5, mayo, pp. 6I-64. 
Ramírez, Ignacio, Gumersindo Mendoza, Luis Malanco e Ignacio Cornejo I870 "Bosques y arbolados", Boletín de la Sociedad Mexicana de Geografía y Estadistica, $2^{a}$ época, tomo II, pp. 14-24.

Río de la Loza, Leopoldo

I9II "Tala de bosques y exportación de maderas" y"Proyecto de ordenanzas de bosques, de arbolados y de exportación de maderas", en Juan Manuel Noriega (comp.), Escritos de Leopoldo Río de la Loza, México, Secretaría de Instrucción Pública y Bellas Artes-Imprenta de Ignacio Escalante, pp. 329-334 y 335-347.

Sanz, Nuria y Carlos Tejeda

2016 México y la unesco / unesco y México: Historia de una relación, México, unesco Oficina en México.

Simonian, Lane

1999 La defensa de la tierra del jaguar. Una bistoria de la conservación en México, México, conabio-Instituto Nacional de Ecología-Semarnap.

UNESCO

1996 Reservas de la biosfera: La Estrategia de Sevilla y el Marco Estatutario de la Red Mundial, París, unesco.

Urquiza García, Juan Humberto

2014 Ciencia forestal, propiedad y conservación para el desarrollo nacional. Los estudios y trabajos ambientales de Miguel Ángel de Quevedo: una historia de su influencia en las politicas de conservación de las cuencas hidrológicas (1890-1940), tesis doctoral inédita, Facultad de Filosofía y Letras, UnAM. Urquiza García, Juan Humberto

2018 "La influencia de Alexander von Humboldt en el pensamiento conservacionista de las Américas", en Pedro Urquijo (ed.), Huellas en el paisaje. Geografía, bistoria y ambiente en las Américas, Morelia, Centro de Investigaciones en Geografía Ambiental-unAm, 2019 (en prensa).

Vargas Márquez, Fernando y Susana Escobar (comps.)

2002 Áreas Naturales Protegidas de México con decretos Federales, México: Semarnap-Red para el Desarrollo Sostenible.

Vargas Palestina, Ernesto

2019 Reservas naturales destinadas a conservación de la fauna en México: 1928-

Wakild, Emily 1939, Tesis de Maestría en Filosofía de la Ciencia, unam.

201 Revolutionary Parks. Conservation, Social Justice, and Mexico's National Parks, 1910-1940, Tucson, University of Arizona Press. 
Worster, Donald,

2008 "La era de la ecología”, en: Guillermo Castro Herrera (sel., trad. y pres.), Transformaciones de la Tierra. Donald Worster, Montevideo, Coscoroba Ediciones, pp. 9-18.

Zinser, Juan

1940 "Protección de la fauna silvestre en América (Trabajo presentado al Congreso Panamericano de Washington)", México Forestal, tomo xviII, 5-6, mayo-junio, pp. 50-52.

\section{Decretos y reglamentos}

I829 "Decreto expedido por el Libertador, sobre las reglas que se han de observar para extraer maderas preciosas y de construcción de los bosques", Guayaquil a 3I de julio de i829. Disponible en http://www. cervantesvirtual.com/obra/decreto-expedido-por-el-libertador-sobrelas-reglas-que-se-han-de-observar-para-extraer-maderas-preciosas-yde-construccion-de-los-bosques-guayaquil-a-3I-de-julio-de-I829--o/ (consulta: 10/05/2018)

I878 "Reglamento Expedido por el Ministerio de Fomento á que deben sujetarse los cortadores de árboles en terrenos nacionales", en: Manuel Dublan y José María Lozano, Legislación Mexicana. Colección Completa de las Disposiciones Legislativas expedidas desde la Independencia de la República, México, Imprenta de Comercio, pp. 160-162.

I893 “Circular Día de Árboles", La Sombra de Arteaga. Periódico Oficial del Gobierno del Estado de Querétaro, 6 de junio, p. 27 I

I896 "El Día de Árboles", La Sombra de Arteaga. Periódico Oficial del Gobierno del Estado de Querétaro, 15 de marzo, p. 88

I897 "Reservas de terrenos para bosques" en Memoria presentada al Congreso de la Unión por el Secretario de Estado y del Despacho de Fomento, Colonización é Industria de la República Mexicana Ingeniero Manuel Fernández Leal. Corresponde a los años transcurridos de 1892 a 1896, México, Oficina Tipográfica de la Secretaría de Fomento, pp. 390-392.

I898 "Julio I ${ }^{\circ}$ de 1895. Circular de la Secretaría de Fomento. Manda que los terrenos baldíos y nacionales en Tehuantepec, se reserven para montes nacionales y para colonización”, en Adolfo Dublán y Adalberto A. Esteva (comps.), Legislación Mexicana ó Colección completa de las Disposiciones 
Legislativas expedidas desde la Independencia de la República. Arreglada por los Licenciados Adolfo Dublán y Adalberto A. Esteva. Continuación de la ordenada por los Lics. Manuel Dublán y José María Lozano, tomo xxv, México, Imprenta de Eduardo Dublán, pp. 267-268.

I899 "Mayo io de I898. Acuerdo de la Secretaría de Fomento. Ordena que el terreno llamado «Monte vedado del Mineral del Chico,» se reserve para un bosque nacional y se propongan las medidas conducentes para conservar los bosques que existen en él", en Adolfo Dublán y Adalberto A. Esteva (comps.), Legislación Mexicana ó Colección completa de las Disposiciones Legislativas expedidas desde la Independencia de la República. Arreglada por los Licenciados Adolfo Dublán y Adalberto A. Esteva. Continuación de la ordenada por los Lics. Manuel Dublán y José María Lozano, tomo xxix, México, Imprenta de Eduardo Dublán, p. I30.

I913 "Ley sobre ocupación y enajenación de terrenos baldíos de los Estados Unidos Mexicanos del 26 de marzo de I894," en Colección de Leyes sobre tierras y disposiciones sobre ejidos publicada por orden de la Secretaría de Fomento. Comprende del año de 1863 a 1912, México, Imprenta y Fototipia de la Secretaria de Fomento, pp. 62-80.

I913 "Reglamento para la Explotación de los Bosques y Terrenos Baldíos y Nacionales y permisos de caza y pesca", en Secretaría de Agricultura y Fomento, Colección de Leyes sobre tierras y disposiciones sobre ejidos publicada por orden de la Secretaría de Fomento. Comprende del año de 1863 a 1912, México, Imprenta y Fototipia de la Secretaria de Fomento, pp. IO3-I27.

I917 "El terreno nacional ubicado en la Municipalidad de Cuajimalpa, conocido con el nombre de «Desierto de los Leones», cuya superficie es de mil quinientas veintinueve hectáreas, se declara «Parque Nacional», conservando los linderos que actualmente tiene", Boletín Oficial de la Secretaría de Fomento, tomo II, 4 a época, núm. 8, noviembre, pp. 640$64 \mathrm{I}$.

1923 "Resolución en el expediente de dotación de tierras, promovido por vecinos de la ciudad de Puruándiro, Estado de Michoacán”, Diario Oficial, México, 28 septiembre, tomo xxv, núm. 24, pp. 334-336.

1926 "Ley Forestal", Diario Oficial, México, 24 abril, pp. I05I-I055.

1934 "Acuerdo que declara Zonas Protectoras Forestales los terrenos cubiertos de arbolado, situados en las Cuencas Hidrográficas de los Sistemas 
Nacionales de Riego en construcción o proyecto", Diario Oficial, México, 3 de enero, pp. 23-28.

1935-1936 "Se prohíbe la introducción en aguas interiores de cualquier especie animal o vegetal", Boletín del Departamento Forestal y de Caza y Pesca, I(2), noviembre I935-enero 1936, pp. 82-83.

1937 "Decreto que promulga el Convenio celebrado entre México y los Estados Unidos de América para la protección de aves migratorias y mamíferos cinegéticos", Diario Oficial, México, 15 de mayo, pp. 2-4.

1978 "Decreto por el que se declara de interés público el establecimiento de la zona de protección forestal de la cuenca del río Tulijah, así como de la reserva de la biósfera Montes Azules, en el área comprendida dentro de los límites que se indican", Diario Oficial, México, I2 enero, pp. 6-8. 1988 "Ley General del Equilibrio Ecológico y la Protección al Ambiente", Diario Oficial, México, 28 enero, pp. 23-57.

2009 "Decreto de Chuquisaca, a I9 de diciembre de 1825 " en Fundación Biblioteca Ayacucho, Simón Bolivar. Doctrina del Libertador, Caracas, Fundación Biblioteca Ayacucho-Banco Central de Venezuela.

Juan Humberto Urquiza García

Licenciado y maestro en Estudios Latinoamericanos y doctor en Historia por la Universidad Nacional Autónoma de México. Es investigador de la Coordinación de Humanidades de la misma casa de estudios. Sus líneas de trabajo abordan la historia ambiental y de la conservación en México y América Latina. Es miembro del Sistema Nacional de Investigadores del Consejo Nacional de Ciencia y Tecnología.

Citar como: Juan Humberto Urquiza García (2019),“Una historia ambiental global: de las reservas forestales de la nación a las reservas de la biosfera en México", Iztapalapa. Revista de Ciencias Sociales y Humanidades, núm. 87, año 40, julio-diciembre de 20I9, ISSN: 2007-9176; pp. IOI-I34. Disponible en $<$ http://revistaiztapalapa.izt.uam.mx/index.php/izt/issue/archive $>$. 